\title{
WAVES IN WETLANDS: HURRICANE GUSTAV
}

\author{
Jane McKee Smith ${ }^{1}$, Robert E. Jensen ${ }^{1}$, Andrew B. Kennedy ${ }^{2}$, J. Casey Dietrich ${ }^{2,3}$, and \\ Joannes J. Westerink ${ }^{2}$
}

\begin{abstract}
Few wave measurements have been made in wetlands during high-energy, surge events, such as hurricanes. During Hurricane Gustav in 2008, many nearshore wave measurements were made in Southeastern Louisiana. These data are used to verify a nearshore wave modeling system and to explore the characteristics of hurricane waves in wetlands. The modeling system consists of the wave generation model WAM, the nearhsore wave model STWAVE, and the circulation model ADCIRC. The measurements confirm reasonable success in modeling the waves. The measurements and modeling also expose some of the problems of measuring waves in highly-variable water depths under hurricane forcing and modeling waves in rapidly degrading wetlands.
\end{abstract}

Keywords: Hurricane Gustav; wave modeling; surge modeling; wetlands; marshes; wave dissipation

\section{INTRODUCTION}

Hurricane Katrina in 2005 brought severe flooding to southeastern Louisiana due to waves and storm surge. Post-storm analysis of the Hurricane Katrina waves and water levels using numerical models indicate the importance of wetlands in reducing wave energy and water levels in key, nearcoast areas (USACE 2006, Wamsley et al. 2009). Unfortunately, measurements were sparse during Katrina and no wave measurements were taken in wetlands to validate these models. Making measurements in hurricanes is a difficult endeavor because of the uncertainty of when and where hurricanes will develop and make landfall.

Hurricane Gustav was one of eight hurricanes that formed during the 2008 Atlantic hurricane season. Gustav made landfall in Haiti, Jamaica, and Cuba, before making its final landfall on the Louisiana coast of the US. The maximum intensity of Gustav was Category 4 on the Saffir-Simpson scale prior to landfall in Cuba. Gustav made landfall near Cocodrie, Louisiana, around 1500 UTC on 1 September 2008 as a Category 2 storm (maximum wind speed of $46 \mathrm{~m} / \mathrm{s}$ ). The track of Hurricane Gustav is shown in Figure 1. Eleven deaths in the US resulted directly from the storm (with another 41 associated deaths), and the storm caused an estimated $\$ 4.3$ mill damages in the US (Bevin and Kimberlain 2009). Surges up to $4 \mathrm{~m}$ occurred along the Louisiana coast southeast of New Orleans (Dietrich et al., in review). Storm surge and waves caused overtopping of a few levees and floodwalls in the New Orleans metropolitan area, but did not cause significant inundation within the protected areas. Prior to Hurricane Gustav, wave gauges were deployed along the Louisiana coast and in Biloxi, Caenarvon, and Terrebonne Marshes. In this paper wave measurements from Hurricane Gustav are used to validate the wave model STWAVE and investigate wave transformation and dissipation in wetlands. This paper describes the measurements, the modeling methodology, and the comparison of the model and measurements.

\section{MEASUREMENTS}

The National Oceanic and Atmospheric Administration's (NOAA) National Data Buoy Center (NDBC) operates buoys throughout the Gulf of Mexico. These discus buoys have diameters that range from $3 \mathrm{~m}$ in shallower depth to $10-12 \mathrm{~m}$ in deeper water. The buoys measure heave acceleration or vertical displacement, which are integrated to derive wave properties including significant height, peak and mean period, and mean direction (http://www.ndbc.noaa.gov/). These measurements are used in this study to validate the basin-scale wave modeling in the Gulf. The locations of NDBC buoys in the Gulf of Mexico are shown in Figure 1.

\footnotetext{
${ }^{1}$ Coastal and Hydraulics Laboratory, Engineer Research and Development Center, 3909 Halls Ferry Road, Vicksburg, MS, 39180-6199, USA

${ }^{2}$ Department of Civil Engineering and Geological Sciences, University of Notre Dame, 156 Fitzpatrick Hall, Notre Dame, IN, 46556, USA

${ }^{3}$ Presently: University of Texas, Institute for Computational Engineering and Sciences, 1 University Station C0200, Austin, TX, 78712, USA
} 


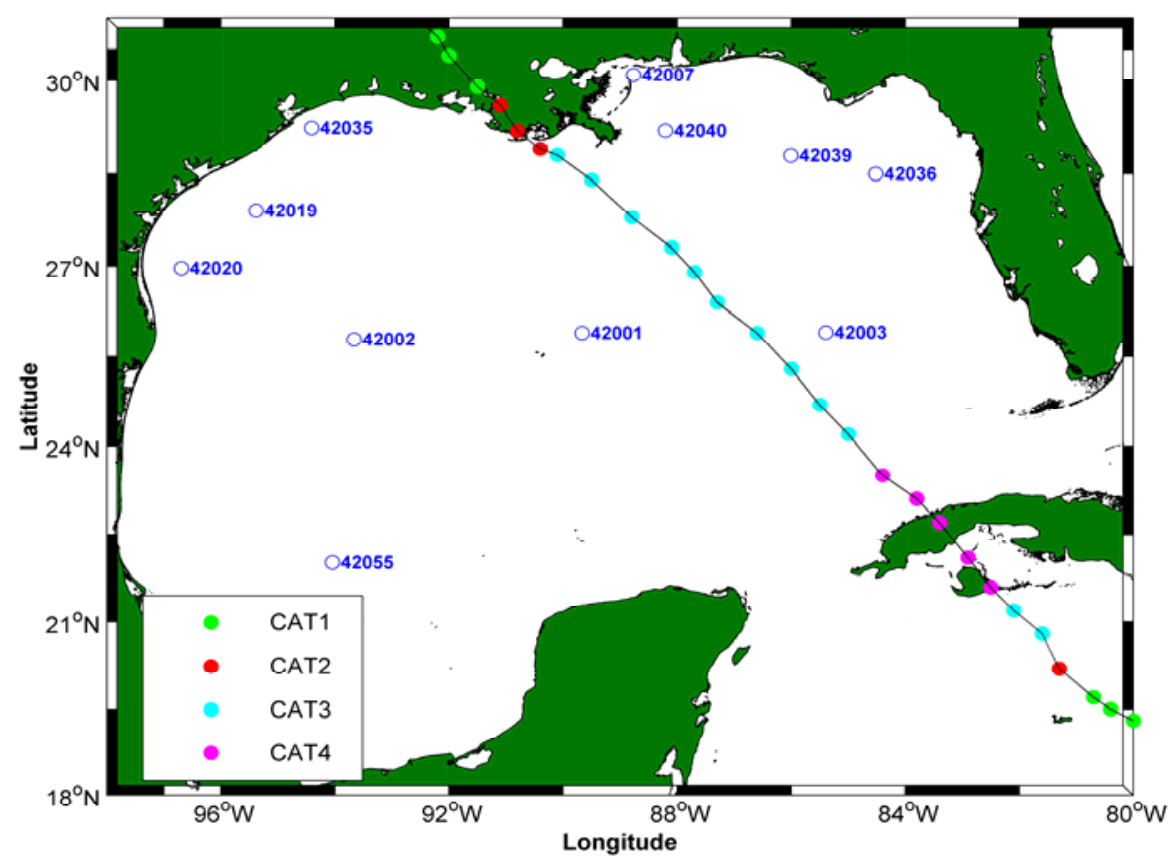

Figure 1. Hurricane Gustav track and Gulf of Mexico NDBC buoy locations.

Prior to Hurricane Gustav, the Corps of Engineers, Coastal and Hydraulics Laboratory (CHL), deployed wave gauges in marshes east of New Orleans and south of New Orleans. CHL deployed three bottom-mounted pressure gauges in Biloxi Marsh (CHL10510, CHL10513, and CHL10504) and three in Terrebonne Marsh (CHL10512, CHL10508, and CHL10514) in depths of 0.5-1.2 m. The gauges were YSI 600XLM pressure gages and were sampled hourly at $2 \mathrm{~Hz}$. Measured absolute pressures were converted to water depths using records of atmospheric pressure, and significant wave heights and mean and peak wave periods were computed using standard spectral methods. These gauges were deployed and retrieved by boat. The locations of the CHL gauges are shown in Figure 2.

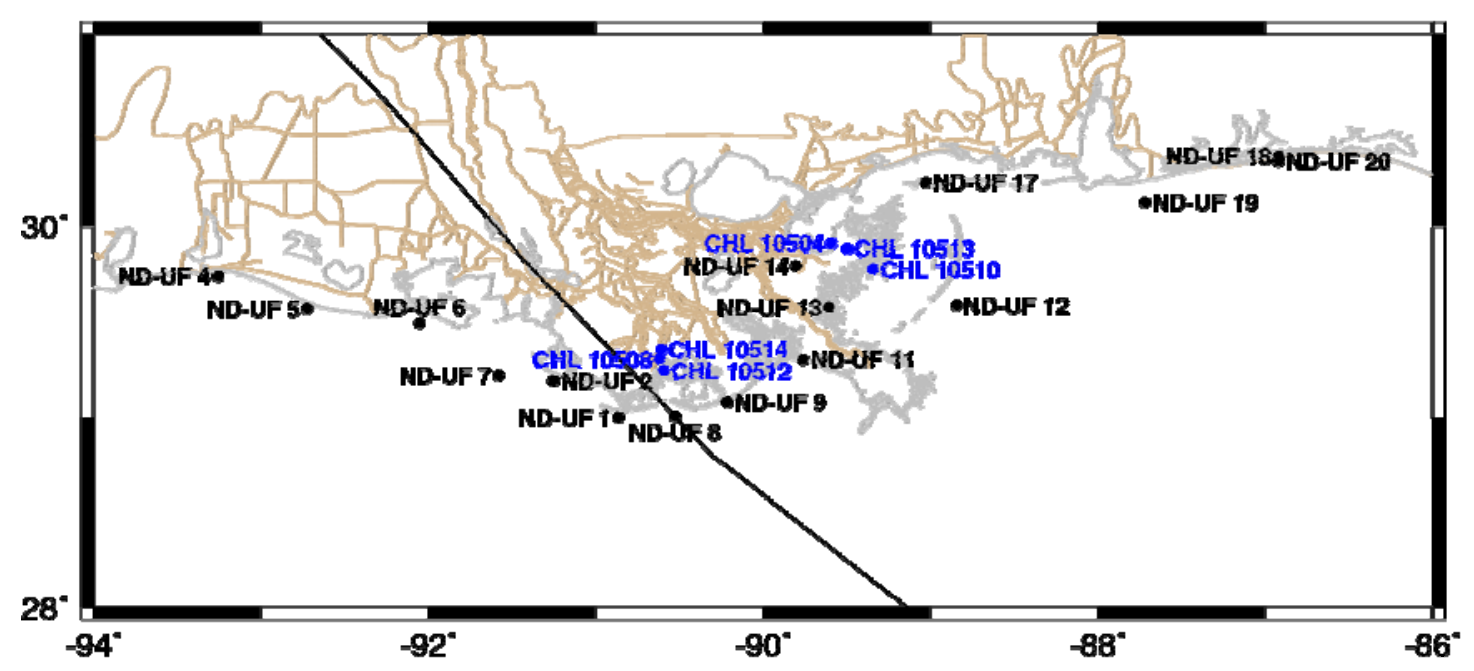

Figure 2. Nearshore gauge locations overlaid on the shoreline (gray) and Gustav track.

A joint project of the University of Notre Dame and the University of Florida (ND-UF) deployed additional gauges by helicopter. Two of these gauges were placed in Caernarvon Marsh (ND-UF 13 and ND-UF 14) southeast of New Orleans and six adjacent to southeastern Louisiana marshes (ND-UF 17, ND-UF 12, ND-UF 11, ND-UF 9, ND-UF 8, and ND-UF 1). Additional ND-UF gauges were deployed to the east (ND-UF 18-20) and west (ND-UF 4-5), but they are not used in this analysis. The 
ND-UF gauges measured waves and water levels using bottom-mounted 100 PSI absolute (689 kPa) piezoelectric silicon pressure sensor recording continuously at $1 \mathrm{~Hz}$ (Kennedy et al. 2010). The gauges were deployed in depths of 1.4 to $14 \mathrm{~m}$. These gages were deployed over a two-day period prior to Gustav's landfall using helicopters, and were retrieved using boats and divers after the storm. Measured absolute pressures were converted to water depths using records of atmospheric pressure. Surge elevations were computed as the low-pass filtered water levels, and significant wave heights were computed using standard spectral methods, corrected using computed depth-averaged currents.

Analysis of the inner marsh gauges deployed by both CHL and ND-UF resulted in peak wave periods around $2 \mathrm{sec}(0.5 \mathrm{~Hz})$ at the peak of the storm, which were near or at the high-frequency cutoff for the spectral analysis (total water depths with surge were $\sim 3 \mathrm{~m}$ ). The high-frequency peaks in the spectra near the cut-off can be a result of amplification of noise due to large values of the pressure response function (applied to account for the depth attenuation of short-period wave components). Wave height in such situations may be either over-estimated (due to amplification of noise) or underestimated (due to truncation of the energetic part of the spectrum). Wave periods would generally be under-estimated. In most applications, these truncated spectra would be disregarded for model verification, but for this application they provide valuable information about what was not measured. The measurements show that large, longer-period waves are not present in the wetlands (waves with periods of 10-15 sec and wave heights of one to several meters that exist outside the wetlands).

\section{MODELING METHODOLOGY}

Hurricane surge and waves are calculated with a suite of coupled models (USACE 2006). The models include the wave generation model WAM (Komen et al. 1994), the nearshore wave generation and transformation model STWAVE (Smith et al. 2001, Smith 2007), and the circulation model ADCIRC (Westerink et al. 2009). The STWAVE and ADCIRC models exchange water levels and wave stresses.

Hurricane wind fields for Gustav were developed using NOAA's Hurricane Research Division Wind Analysis System (H*Wind) to assimilate extensive wind measurements from many sources (Powell et al. 2010). To provide forcing for the circulation and wave models, the $\mathrm{H}^{*} \mathrm{Wind}$ fields are blended with larger scale winds using the Interactive Objective Kinematic Analysis (IOKA) system (Cox et al. 1995). The resulting wind fields apply to the reference condition of $10 \mathrm{~m}$ height, $30 \mathrm{~min}$ sustained wind speed, and marine exposure. The wind fields are used to drive the wave and circulation models.

WAM is a third-generation, discrete spectral wave model that solves the action balance equation, accounting for arbitrary water depth in source/sink term specification to compute the generation and dissipation of wave action (Komen et al. 1994, Günther 2005). WAM was run on a Gulf-wide mesh with fixed 0.05-deg resolution. The WAM grid domain is shown in Figure 1. WAM was applied with 28 frequency bins that increase in bandwidth logarithmically, and 24 direction bins with a constant width of $15 \mathrm{deg}$. WAM generated spectra at approximately the $30-\mathrm{m}$ contour that were applied as boundary conditions for the nearshore STWAVE grids.

ADCIRC solves the 2D shallow-water equations for water levels and the vertically-integrated momentum equations for currents (Kolar et al. 1994, Luettich and Westerink 2004, Dawson et al. 2006). ADCIRC operates on an unstructured mesh that extends from the western North Atlantic through the Gulf of Mexico and Caribbean Sea. This large mesh domain allows tides to be specified at a boundary outside the Gulf of Mexico and storms to be started inside the domain but far from the area of interest. The mesh resolution extends from $15-20 \mathrm{~km}$ in deep water to $100-200 \mathrm{~m}$ in the wave breaking zones to $20-50 \mathrm{~m}$ in fine-scale channels. The high-resolution mesh includes over 5 mill nodes and nearly 10 mill elements (Dietrich in review). The mesh bathymetry and topography were compiled from ETOPO1 in deep water (Amante and Eakins 2009), Coastal Relief DEMs (NOAA 2008) and recent surveys by the Corps of Engineers and NOAA in the nearshore, and LiDAR surveys further inland (http://atlas.lsu.edu/lidar/). Hydraulic friction is computed in ADCIRC using a Manning's $n$ formulation, with spatially-variable values that are applied based on land-cover databases (Bunya et al. 2010). Levees are defined using sub-mesh-scale weirs (Westerink et al. 2008). Levee and road heights reflect pre-Gustav conditions. ADCIRC applies a factor of 1.09 to convert from 30-minaveraged wind speeds to 10-min-averages, and directional wind reduction factors are applied (Bunya et al. 2010). ADCIRC was applied with a 1-s time step. ADCIRC provides wind fields and water surface levels to the nearshore wave model STWAVE. After STWAVE is run, ADCIRC is rerun with wave radiation stress input. 
STWAVE (Smith et al. 2001, Smith 2007) solves the steady-state wave action balance equation along piecewise, backward-traced wave rays on a Cartesian grid. STWAVE utilized 45 frequency bins, on the range $0.0314-2.08 \mathrm{~Hz}$ and increasing in bandwidth logarithmically $(\Delta \mathrm{f} / \mathrm{f} \approx 0.1)$, and 72 directional bins of constant width $5 \mathrm{deg}$. The parallel, full-plane STWAVE was applied at 200-m resolution on two nearshore grids covering the area $137 \mathrm{~km}$ east and $165 \mathrm{~km}$ west of the Mississippi River (Figure 3). Grid bathymetry and topography were interpolated from the ADCIRC mesh. Winds are also interpolated from the ADCIRC and converted back to 30-min averages. The bottom friction source term in STWAVE is formulated with the Manning friction coefficient, $n$,

$$
S_{b f}=\frac{-1}{g}\left(\frac{g n^{2}}{d^{1 / 3}}\right) \frac{\sigma^{2}}{\sinh ^{2} k d} E(f, \theta) u_{r m s}
$$

Where $\mathrm{g}$ is gravitational acceleration, $\sigma$ is the wave radial frequency $(2 \pi \mathrm{f}), \mathrm{k}$ is wave number, $\mathrm{d}$ is total water depth, $\mathrm{f}$ is frequency, $\theta$ is direction, and $\mathrm{u}_{\mathrm{rms}}$ is root-mean-square bottom velocity. Nearshore wave simulations cover a 3-day period from 31 Aug - 2 Sep 2008 (Julian Days 244-246), as Hurricane Gustav tracked offshore and made land-fall.

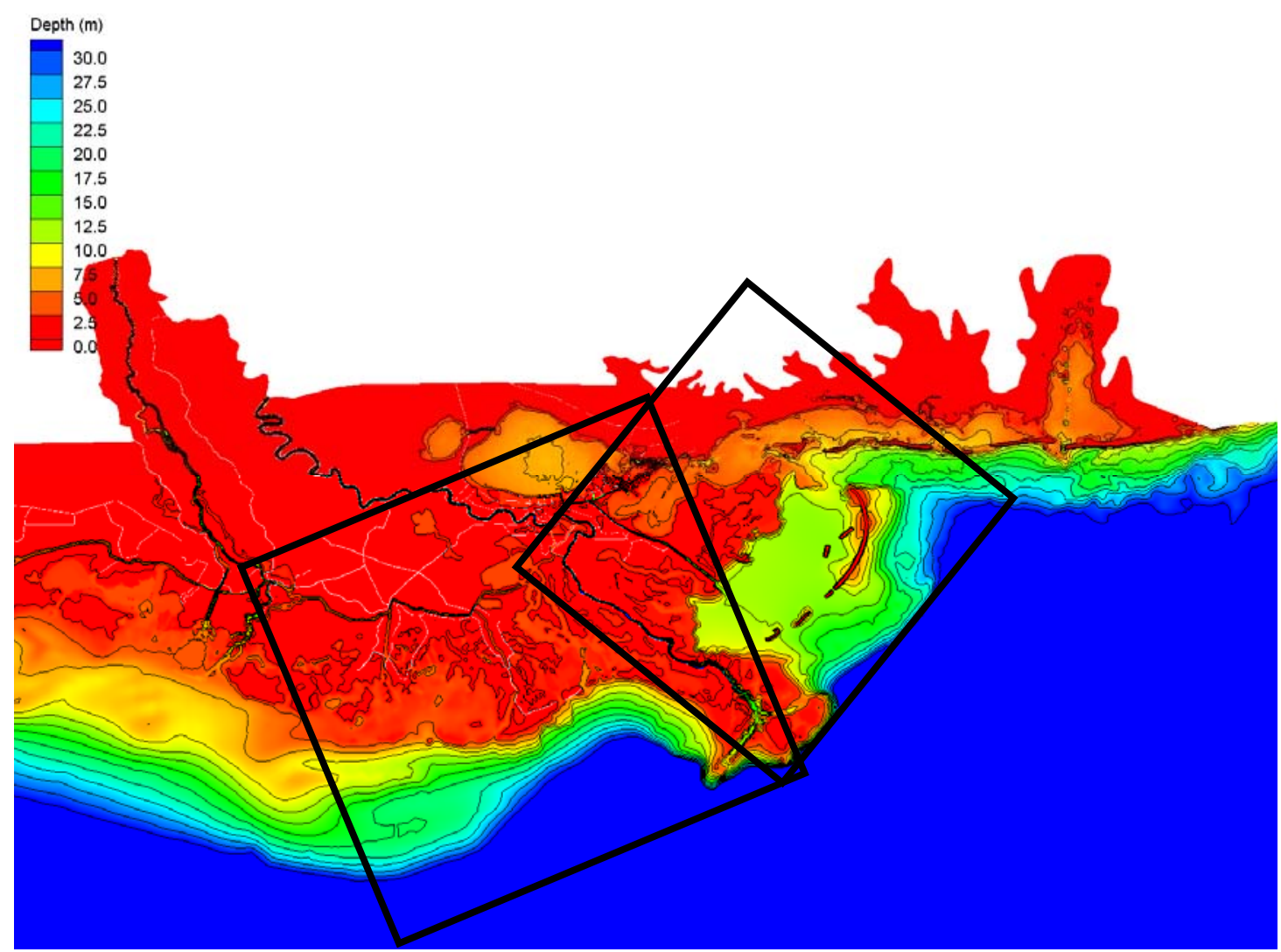

Figure 3. STWAVE South and Southeast domains overlaid on bathymetry.

\section{RESULTS}

Wave heights in the Gulf of Mexico reach $15.8 \mathrm{~m}$ southwest of New Orleans in the WAM simulation. Figure 4 shows the maximum simulated wave height envelope for Hurricane Gustav within the WAM domain. The maximum wave height aligns just to the northeast of the storm track. Figure 5 shows a time history comparison of WAM to the buoy closest to southeast Louisiana and the storm track, NDBC 42040 (Figure 1). The buoy is in a water depth of $274 \mathrm{~m}$. The figure shows excellent agreement of WAM with the measurements. The maximum zero-moment wave height, $\mathrm{H}_{\text {mo, }}$ is $11 \mathrm{~m}$ and peak period, $\mathrm{T}_{\mathrm{p}}$, is $15 \mathrm{sec}$, at the buoy. 


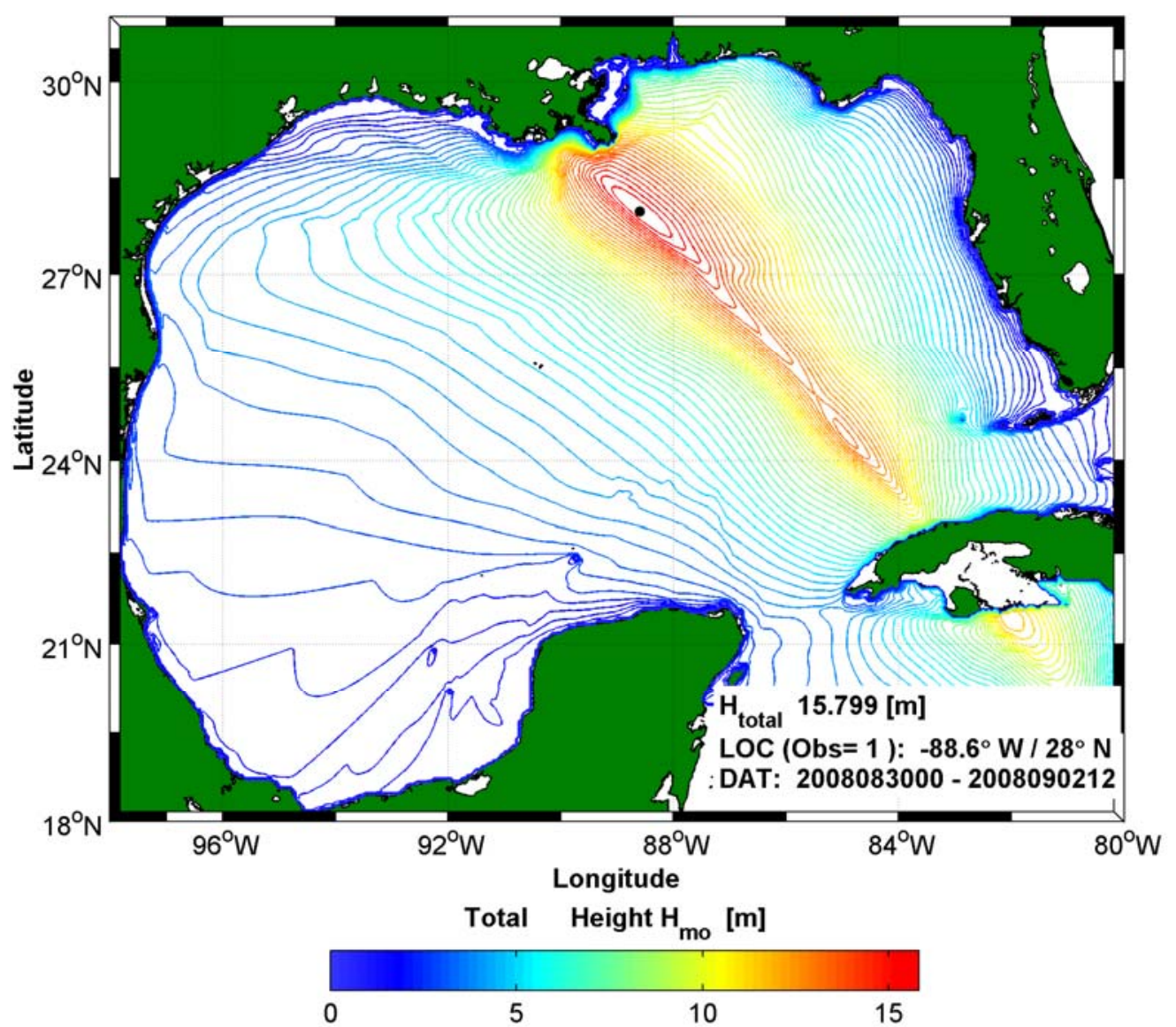

Figure 4. Contours of maximum zero-moment wave height for Gustav calculated by WAM.
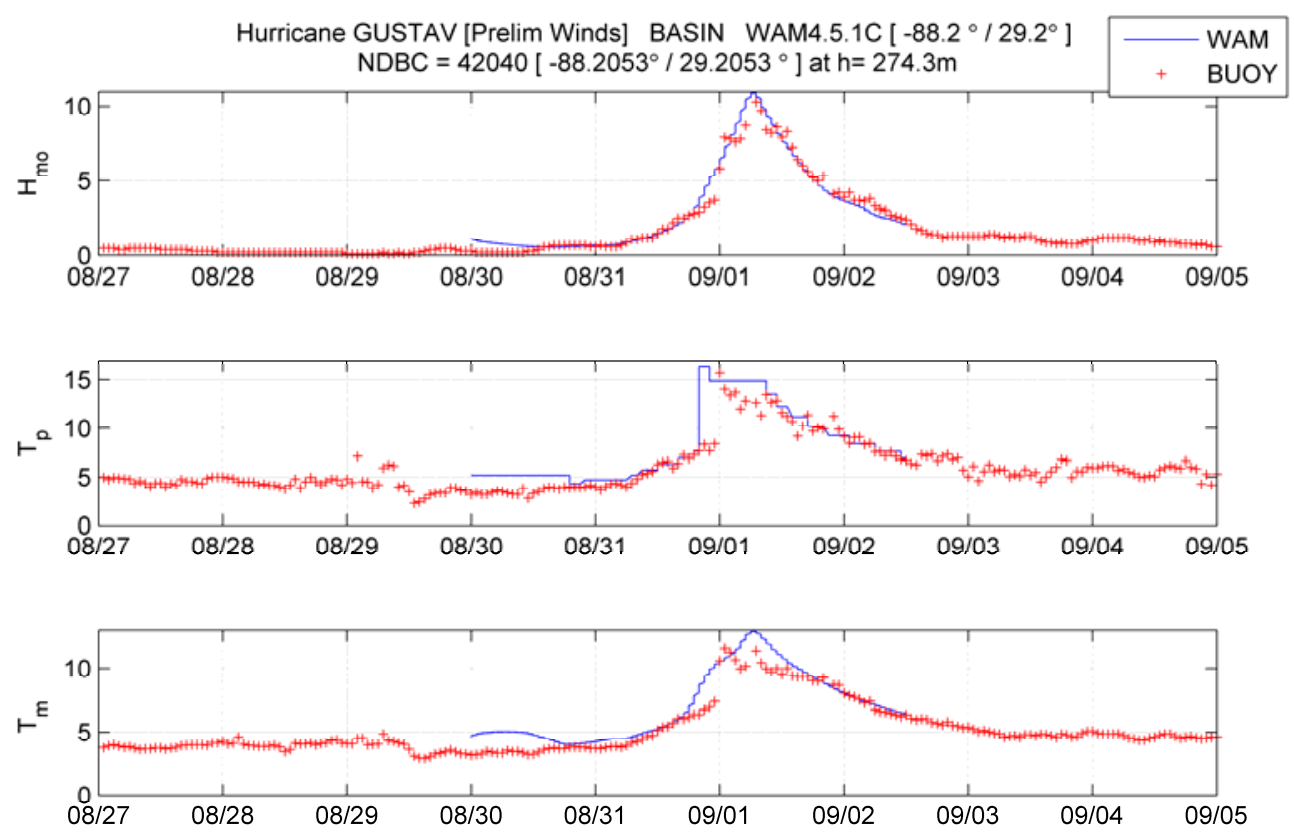

Figure 5. WAM comparison to NDBC buoy 42040. Wave heights are in meters and periods in seconds.

Figures 6 and 7 show the maximum wave height envelope for Hurricane Gustav within the STWAVE Southeast and South domains, respectively. The color contours show the maximum wave 
height for each grid cell and the vectors are the associated mean wave direction. On the Southeast grid, east of the Mississippi River, wave heights decreased across the shelf to a height of 5 to $6 \mathrm{~m}$ along the Chandeleur Islands. The Chandeleurs were significantly degraded during Hurricane Katrina, but still provide significant wave reduction. Wave heights landward of the islands are on the order of 1 $\mathrm{m}$. Some wave growth occurs in the sound behind the islands and wave height increases to approximately $2 \mathrm{~m}$. Within the wetland, the heights are further dissipated. Wave heights in the wetland are 0.5 to $1 \mathrm{~m}$. The wetland gauge positions are shown with red diamonds in Figures 6 and 7 . Similarly, on the South grid, west of the Mississippi River, wave heights decreased across the shelf to a height of 5 to $7 \mathrm{~m}$ along the barrier islands. The barrier islands provide significant wave reduction, and wave heights landward of the islands and in the bays are on the order of 1-2 m. Within the wetlands, the heights are further dissipated to $0.3-1 \mathrm{~m}$. In both domains, wave periods are reduced to $6 \mathrm{sec}$ or less behind the barrier islands and to $2-4 \mathrm{sec}$ in the wetlands at the peak wave conditions.

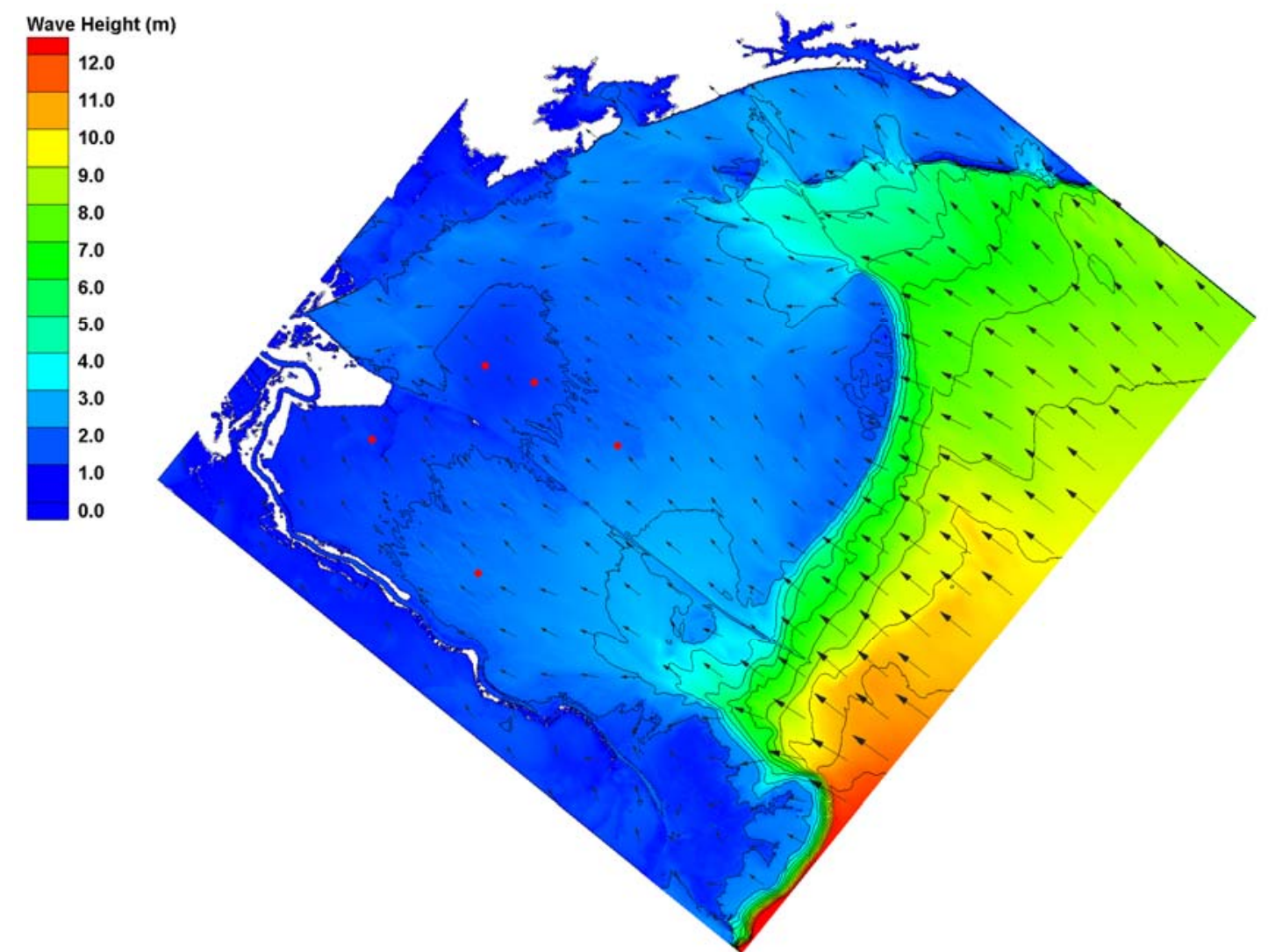

Figure 6. Contours of maximum zero-moment wave height for Gustav calculated for the STWAVE Southeast domain. Wetland gauge locations are shown with red diamonds.

Figure 8 shows comparisons of STWAVE results to the gauges in Biloxi Marsh (CHL10510, 10513 and 10504). CHL10510 is on the outer edge of the marsh and CHL10504 is the most interior gauge. Measured wave heights at the peak of the storm are just over $1 \mathrm{~m}$ at the outer edge of the marsh and 0.45 in the inner marsh. Measured peak wave periods are generally 2-4 sec, with the longer periods at the outer gauge. Figure 9 shows a similar comparison for Caernarvon Marsh (ND-UF 13 and 14). The outer marsh gauge recorded a maximum wave height of $1.3 \mathrm{~m}$ and the inner gauge recorded $0.4 \mathrm{~m}$. Peak periods ranged from $2-7 \mathrm{sec}$, with the longer periods at the outer gauge. Results show relatively good agreement between model estimates and measurements of wave height and peak period. The waves seaward of the wetlands tend to be overestimated by 15 percent. Modeled waves in the wetlands east of the river are in relatively good agreement with measurements of wave height, but model results have somewhat longer peak wave periods. 


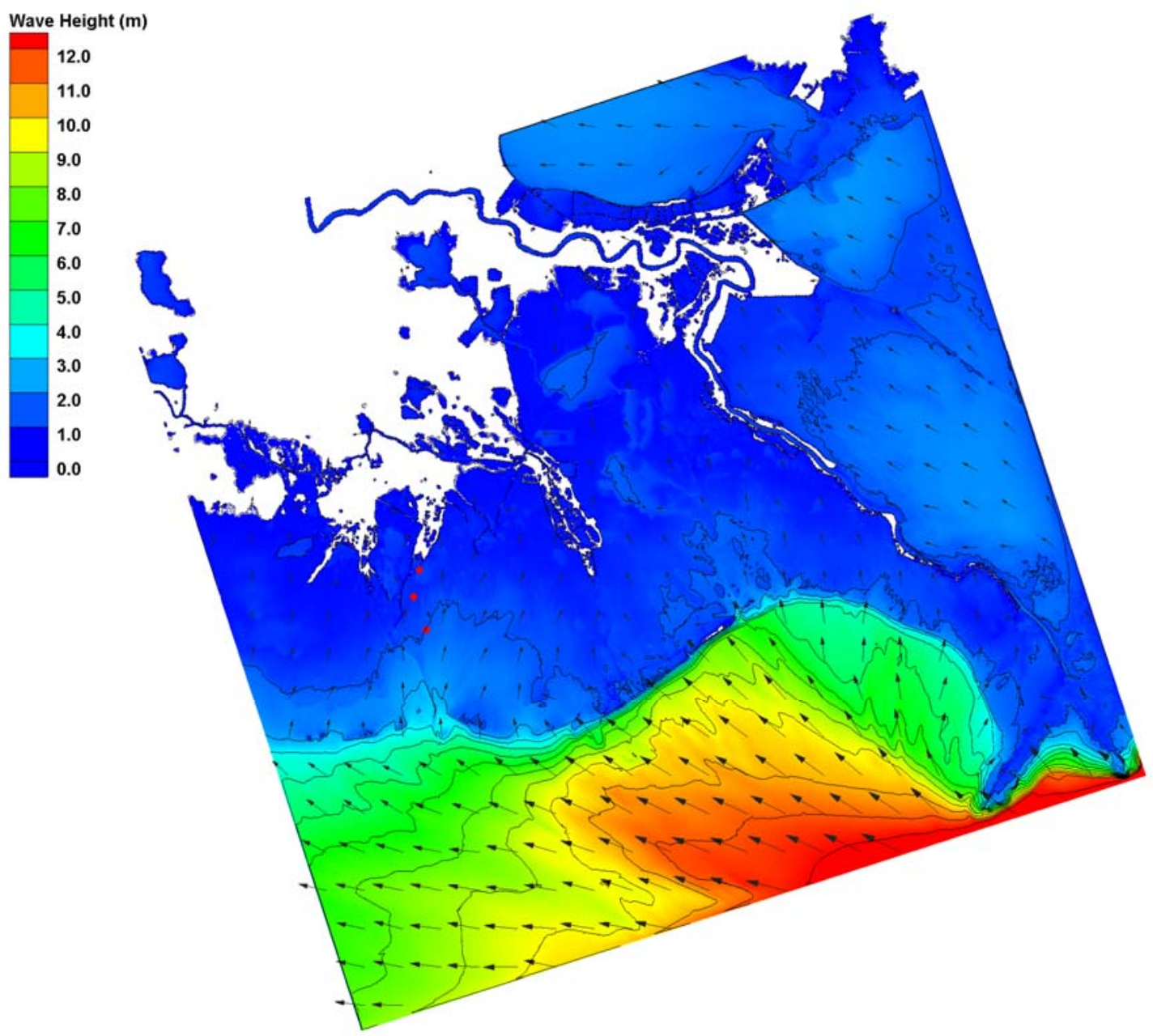

Figure 7. Contours of maximum zero-moment wave height for Gustav calculated for the STWAVE South domain. Wetland gauge locations are shown with red diamonds.

Figure 10 shows comparisons of STWAVE results to the gauges in Terrebonne Bay/Marsh (NDUF8, CHL10512, 10508 and 10514). ND-UF8 is seaward of the barrier islands (Isle Dernieres and Timbalier Island) and CHL10512-10514 are spread from Terrebone Bay into the marsh. At ND-UF8, the maximum simulated wave height is approximately 10 percent greater than the measurement. Within the bay and marsh, the measured wave heights at the peak of the storm range from 0.8 to $0.5 \mathrm{~m}$ and peak periods range from 5 to $2 \mathrm{sec}$. At CHL10512 (outer bay gauge), STWAVE overestimates the wave height by 35 percent, but the two inner gauges in Terrebonne Marsh, STWAVE underestimates wave height by 40 to 50 percent. The underestimation appears to be due to significant marsh degradation compared to the gridded bathymetry and topography (following Hurricane Katrina, greater effort was put into updating survey information east of the river and much less work was done west of the river). Depth-limited breaking, steepness-induced breaking and frictional dissipation are key processes in these simulations, so accurate bathymetry is key.

Figure 11 shows peak-to-peak comparisons of the maximum modeled versus measured wave height at all gauges within the STWAVE domains (including NDBC 42007, Figure 1). The average percent error is -1 percent (overestimate). The root-mean-square error is $0.6 \mathrm{~m}$ or approximately 25 percent (17 percent excluding the Terrebonne Bay measurements). Comparisons of frequency spectra throughout the spatial domain under these strongly forced conditions show fair agreement with the data, although the measured spectra show more complexity in the spectral shape than the model results. 

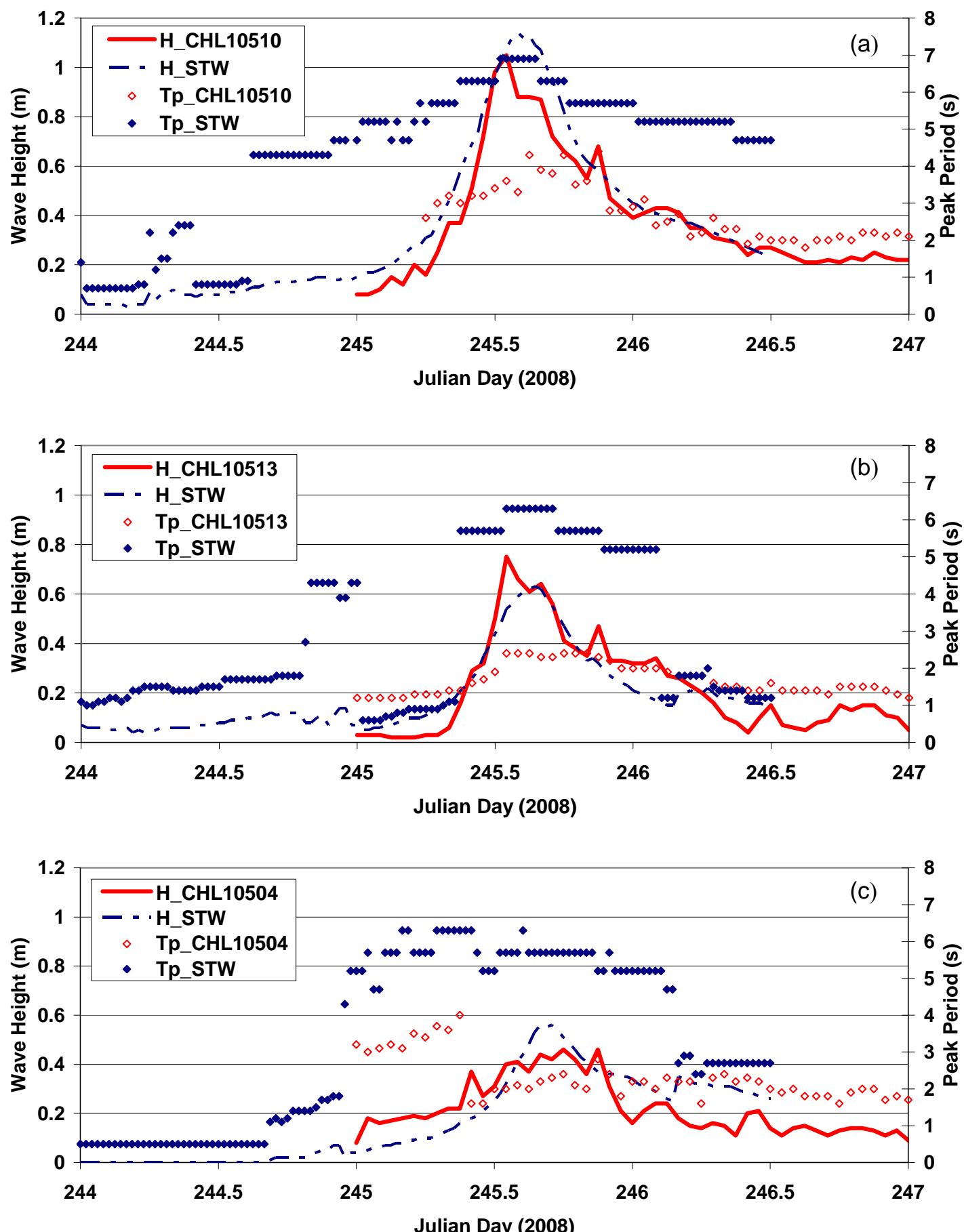

Figure 8. Time history comparisons of measured and modeled zero-moment wave height and peak period in Biloxi Marsh for Hurricane Gustav. (a) CHL10510 outer marsh, (b) CHL10513 middle marsh, and (c) CHL10504 inner marsh. 

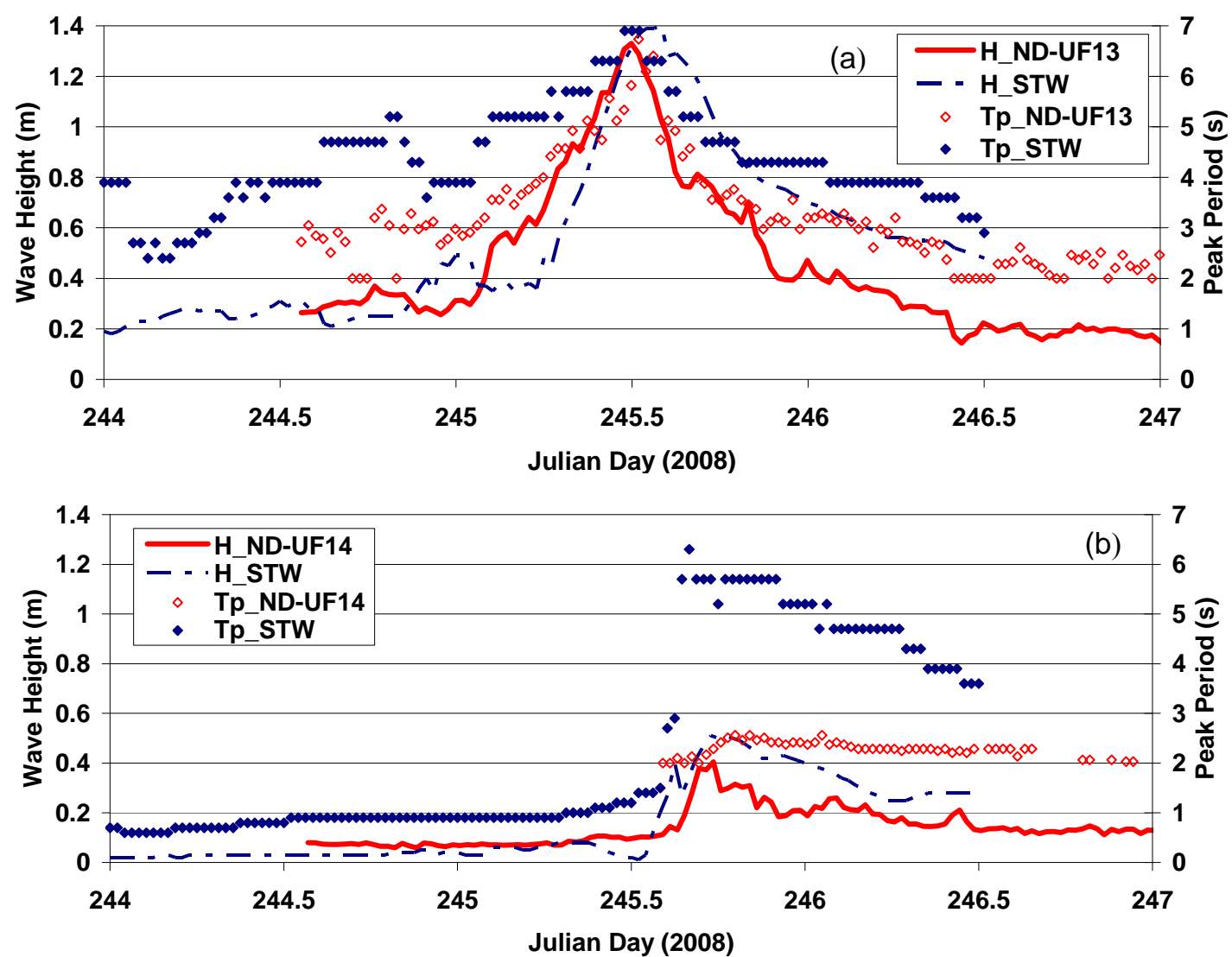

Figure 9. Time history comparisons of measured and modeled zero-moment wave height and peak period in Caenarvon Marsh for Hurricane Gustav. (a) ND-UF13 (b) ND-UF14 inner marsh.

\section{SUMMARY}

Wave measurements from Hurricane Gustav were used to evaluate the nearshore wave model STWAVE for both open and protected marsh areas in southeastern Louisiana. The model WAM was applied on the scale of the Gulf of Mexico and provided offshore boundary conditions for STWAVE. The circulation model ADCIRC was run in parallel with STWAVE and supplied the water levels, which are key to modeling the hurricane waves in shallow wetlands with surge. The measurements confirm model results of large wave height reduction for moderate $(2-3 \mathrm{~m})$ storm surge. Waves outside the barrier islands were in the range of $6-11 \mathrm{~m}$. Wave heights were reduced to $1-2 \mathrm{~m}$ inside the barrier islands. Re-generation occurred behind the barrier islands, and wave heights of 1-2 m were measured and modeled at the marsh fringe. Within the marshes, maximum wave heights were in the range of $0.3-1 \mathrm{~m}$. Short wave periods were observed in the marshes, which indicate waves in the marshes were locally generated. The implication of these results is the confirmation of the importance of barrier islands and marshes in reducing nearshore wave energy in southeast Louisiana and the validation of numerical models for estimating these nearshore processes. Field measurements are a critical asset for understanding hurricane wave processes and improving and validating nearshore wave models. Additional nearshore measurements should be pursued for further validation in more intense storms. 

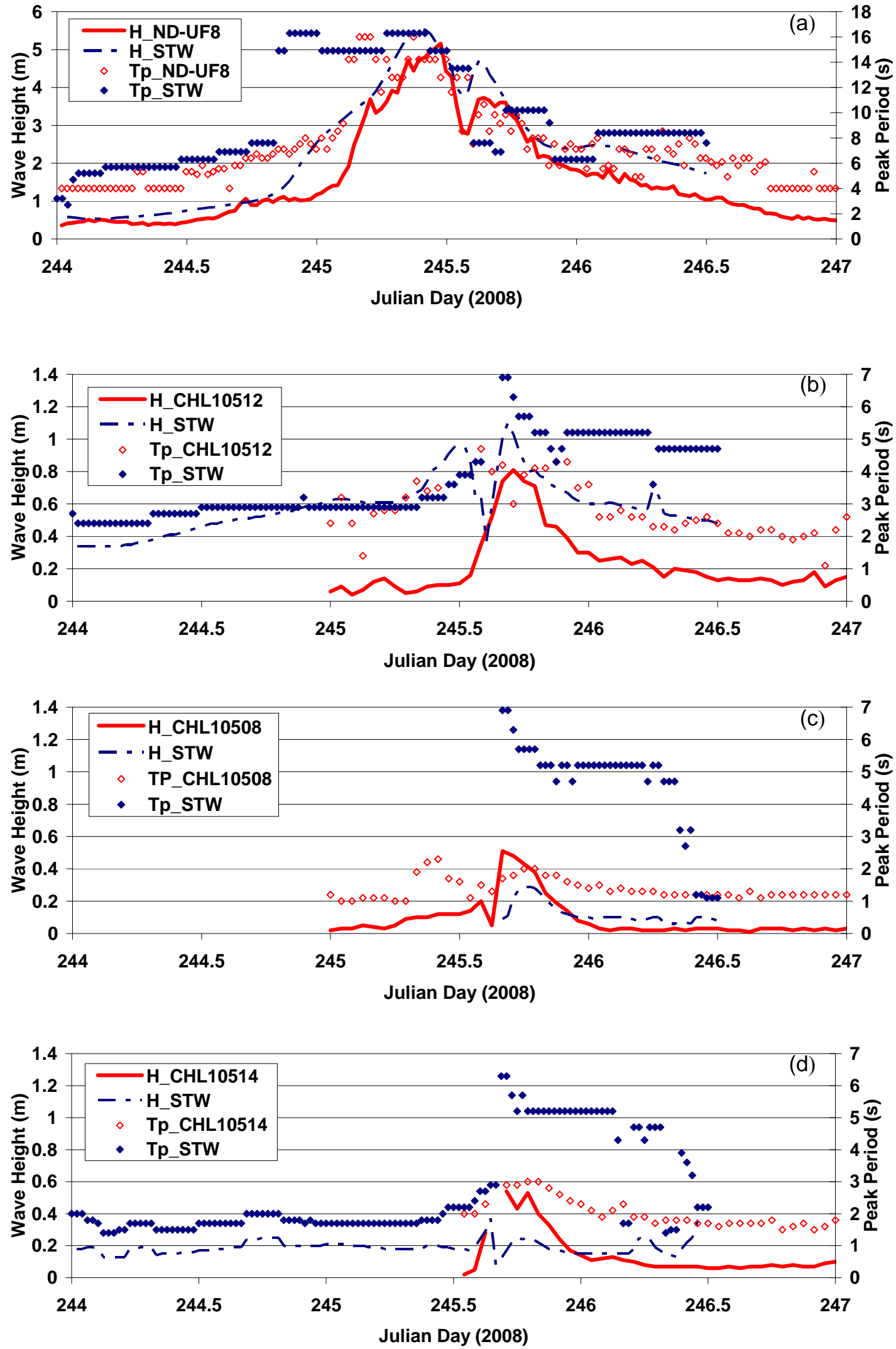

Figure 10. Time history comparisons of measured and modeled zero-moment wave height and peak period in Terrebonne Marsh for Hurricane Gustav. (a) ND-UF8 Barrier Island, (b) CHL10512 outer marsh, (c) CHL10508 middle marsh, and (d) CHL10514 inner marsh. 


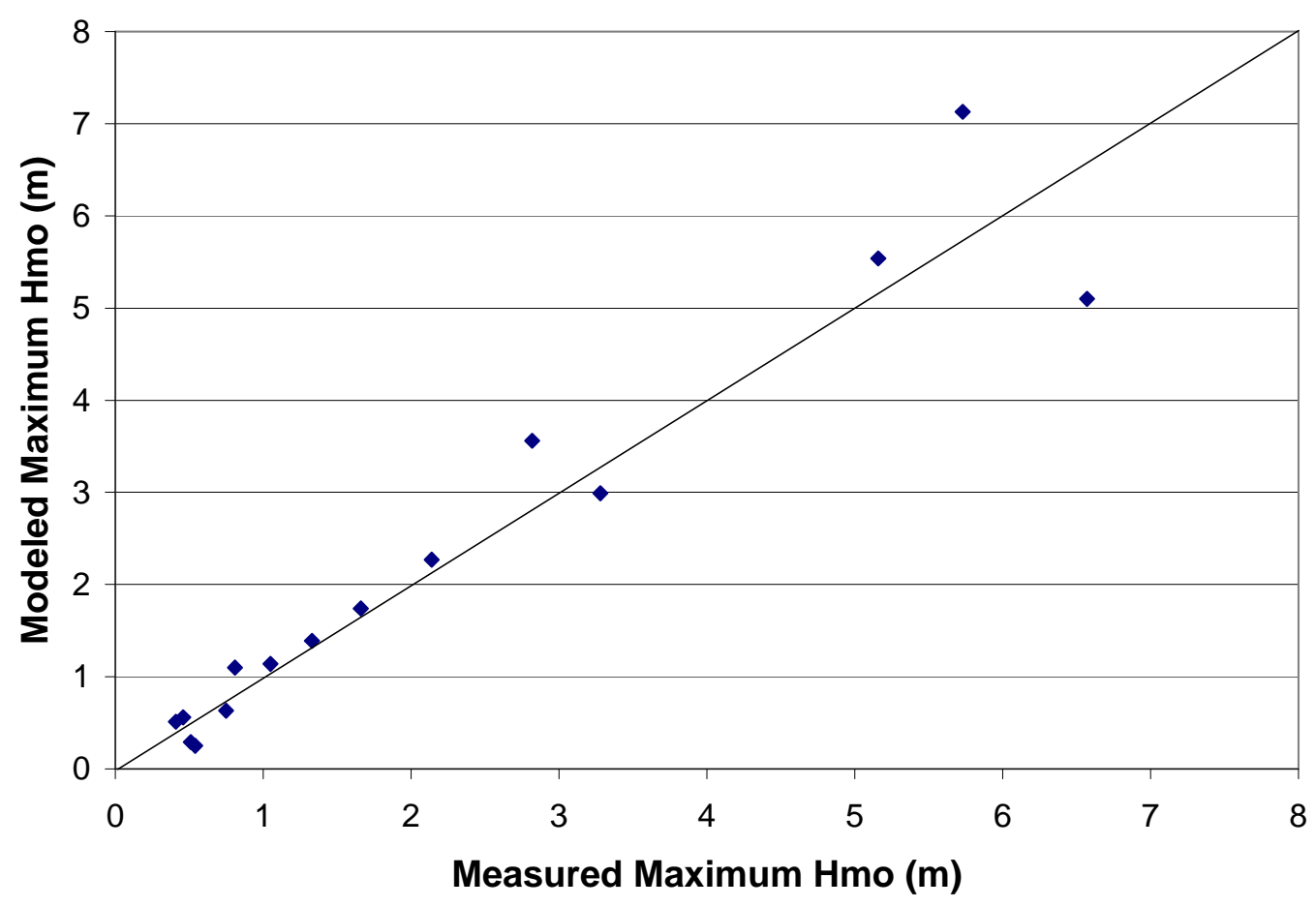

Figure 11. Peak to peak wave height comparison for Hurricane Gustav wave gauges.

\section{ACKNOWLEDGMENTS}

Permission to publish this work was granted by the Chief of Engineers, U.S. Army Corps of Engineers. The CHL Field Data Collection and Analysis Branch members Pat McKinney, Thad Pratt, William Butler and Terry Waller are acknowledged for the collection and analysis of the CHL Gustav Data. The Notre Dame-University of Florida team members Uriah Gravois and Brian Zachry are acknowledged for collection and analysis of the ND-UF Gustav data.

\section{REFERENCES}

Amante, C., and B. W. Eakins, 2009: ETOPO1 1 Arc-Minute Global Relief Model: Procedures, Data Sources and Analysis. NOAA Technical Memorandum NESDIS NGDC-24, 19 pp.

Beven, J.L., and T.B. Kimberlain. 2009. Tropical Cyclone Report Hurricane Gustav AL072008. National Hurricane Center. http://www.nhc.noaa.gov/ms-word/TCR-AL072008 Gustav.doc.

Bunya, S., J.C. Dietrich, J.J. Westerink, B.A. Ebersole, J.M. Smith, J.H. Atkinson, R. Jensen, D.T. Resio, R.A. Luettich, C. Dawson, V.J. Cardone, A.T. Cox, M.D. Powell, H.J. Westerink, H.J. Roberts. 2010. A High-Resolution Coupled Riverine Flow, Tide, Wind, Wind Wave and Storm Surge Model for Southern Louisiana and Mississippi: Part I - Model Development and Validation. Monthly Weather Review, 138(2), 345-377.

Cox, A.T., J.A. Greenwood, V.J. Cardone, and V.R. Swail. 1995. An interactive objective kinematic analysis system. Proc. Fourth Int. Workshop on Wave Hindcasting and Forecasting, Banff, Alberta, Canada, Atmospheric Environment Service, 109-118.

Dawson, C., J.J. Westerink, J.C. Feyen, and D. Pothina. 2006. Continuous, Discontinuous and Coupled Discontinuous-Continuous Galerkin Finite Element Methods for the Shallow Water Equations. Int. J. Numer. Meth. Fluids, 52, 63-88.

Dietrich, J.C., J.J. Westerink, A.B. Kennedy, J.M. Smith, R. Jensen, M. Zijlema, L.H. Holthuijsen, C. Dawson, R.A. Luettich Jr., M.D. Powell, V.J. Cardone, A.T. Cox, G.W. Stone, H. Pourtaheri, M.E. Hop1, S. Tanaka1, L.G. Westerink, H.J. Westerink, Z. Cobell. In rev. Hurricane Gustav (2008) Waves, Storm Surge and Currents: Hindcast and Synoptic Analysis in Southern Louisiana. Submitted to Monthly Weather Review.

Günther, H. 2005. WAM cycle 4.5 version 2.0. Institute for Coastal Research, GKSS Research Centre, Geesthacht, Germany, 38 pp. 
Kennedy, A.B., U. Gravois, B. Zachry, R.A. Luettich, T. Whipple, R. Weaver, J Fleming, Q.J. Chen, and R. Avissar. 2010. Rapidly Installed Temporary Gauging for Hurricane Waves and Surge, and Application to Hurricane Gustav. Continental Shelf Research, 30(16), 1743-1752.

Kolar, R.L., J.J. Westerink, M.E. Cantekin, and C.A. Blain. 1994. Aspects of nonlinear simulations using shallow water models based on the wave continuity equations. Computers and Fluids, 23(3), 1-24.

Komen, G., L. Cavaleri, M. Donelan, K. Hasselmann, S. Hasselmann and P.A.E.M. Janssen. 1994. Dynamics and Modelling of Ocean Waves. Cambridge University Press, UK, 560 pp.

Luettich, R.A., and J.J. Westerink. 2004. Formulation and Numerical Implementation of the 2D/3D ADCIRC Finite Element Model Version 44.XX; 2004. http://adcirc.org/adcirc theory 2004 12 08.pdf

NOAA National Geophysical Data Center, NGDC Coastal Relief Model, Retrieved 01 December 2008, http://www.ngdc.noaa.gov/mgg/coastal/coastal.html

Powell, M. D., S. Murillo, P. Dodge, E. Uhlhorn, J. Gamache, V. Cardone, A. Cox, S. Otero, N. Carrasco, B. Annane, and R. St. Fleur. 2010. Reconstruction of Hurricane Katrina's wind fields for storm surge and wave hindcasting. Ocean Engineering, 37, 26-36.

Smith, J.M. 2007. Full-Plane STWAVE: II. Model Overview. ERDC TN-SWWRP-, U.S. Army Engineer Research and Development Center, Vicksburg, MS.

Smith, J.M., A.R. Sherlock, and D.T. Resio. 2001. STWAVE: Steady-state spectral wave model user's manual for STWAVE version 3.0, ERDC/CHL SR-01-1, U.S. Army Engineer Research and Development Center, Vicksburg, MS.

USACE. 2006. Performance Evaluation of the New Orleans and Southeast Louisiana Hurricane Protection System. Draft Final Report of the Interagency Performance Evaluation Task Force (IPET); Volume IV.

Wamsley, T.V., M.A. Cialone, J.M. Smith, J.H. Atkinson, and J.D. Rosati. 2009. The Potential of Wetlands in Reducing Storm Surge. Ocean Engineering, 37, 59-68.

Westerink, J.J., R.A.Luettich, J.C. Feyen, J.H. Atkinson, C. Dawson, H.J. Roberts, M.D. Powell, J.P. Dunion, E.J. Kubatko, and H. Pourtaheri. 2008. A Basin to Channel Scale Unstructured Grid Hurricane Storm Surge Model as Applied to Southern Louisiana. Monthly Weather Review, 136, 833-864. 